\title{
Fetal haemoglobin and alpha 1 microglobulin as biochemical markers in predicting preeclampsia in late first trimester and early second trimester of pregnancy
}

\author{
S. Vijaya, M. Mahalakshmi*, I. Inbapriyanka
}

Department of Obstetrics and Gynecology, ISO-KGH, Triplicane, Chennai, Tamil Nadu, India

Received: 28 May 2018

Accepted: 26 June 2018

\section{*Correspondence:}

Dr. M. Mahalakshmi,

E-mail: mahalakshmi1977m@gmail.com

Copyright: (C) the author(s), publisher and licensee Medip Academy. This is an open-access article distributed under the terms of the Creative Commons Attribution Non-Commercial License, which permits unrestricted non-commercial use, distribution, and reproduction in any medium, provided the original work is properly cited.

\begin{abstract}
Background: Preeclampsia is a multi system disorder with placenta as the organ of origin and maternal endothelium being the organ of target. According to recent studies, the cell free haemoglobin induces oxidative stress mediated damage to the blood placenta barrier with consequently elevated levels of $\mathrm{HbF}$ in maternal blood. Alpha 1 microglobulin is an endogenous protein with antioxidant property, present in elevated levels in maternal blood in response to oxidative stress. This fact forms the basis for our study. The objective of the present study was to establish association between high levels of fetal hemoglobin and alpha 1 microglobulin in plasma of pregnant women between 10 to 16 weeks of gestational age and subsequent development of preeclampsia.

Methods: This was a prospective cohort study undertaken in the Department of Obstetrics and Gynaecology, ISO KGH, between December 2016 to November 2017. A total of 100 pregnant women were included in the study after getting informed written consent. Both primigravida and multigravida, belonging to age group of 20 to 35 years (singleton/ multiple) between 10 to 16 weeks GA and with BMI between 16 to $35 \mathrm{~kg} / \mathrm{m}^{2}$ were included in the study. A woman with Diabetes mellitus, Hypertension, Renal disease, Epilepsy and Vascular disorders were excluded from the study.

Results: The cut off value for alpha 1 microglobulin was $1.86 \mathrm{ng} / \mathrm{ml}$ and the cut off value of fetal haemoglobin was $1.92 \mathrm{ng} / \mathrm{ml}$ above which the pregnant women develop preeclampsia.

Conclusions: Higher values of fetal hemoglobin and alpha 1 microglobulin in pregnant women between 10 to 16 weeks gestational age positively correlates with development of preeclampsia in those women.
\end{abstract}

Keywords: Alpha 1 microglobulin, Bio-marker, Fetal haemoglobin, Preeclampsia

\section{INTRODUCTION}

Preeclampsia is a systemic syndrome manifesting as "new onset hypertension and proteinuria after 20 weeks of gestation" occurring in about 7 to $15 \%$ of pregnant women.

About $20 \%$ of fetal deaths and $30 \%$ of maternal deaths are due to hypertensive disorders of pregnancy.
Maternal complications include eclampsia, HELLP, pulmonary edema, hypertensive encephalopathy, DIC, acute renal failure. ${ }^{1}$ Fetal complications include FGR, preterm birth, oligohydramnios and intrauterine death. ${ }^{1}$ The major focus was to identify mothers who are at risk of adverse pregnancy outcome.

The primary biochemical, immunologic and genetic basis of preeclampsia remains speculative. Pathogenesis 
include defective invasion of maternal spiral arteries by the trophoblast, endothelial injury leading to activation of coagulation, secretion of endothelial cell toxin, altered endothelial permeability and impairment of vasodepressor function. ${ }^{2,3}$

Recent studies indicated the involvement of free haemoglobin induced oxidative stress in the development of preeclampsia. The oxidative stress damage the blood placenta barrier leading to elevated levels of $\mathrm{HbF}$ in maternal plasma. ${ }^{4}$ In addition, marker for oxidative endogenous protein, alpha 1 microglobulin were found to be elevated. This forms the background for present study.

Newer techniques like proteomics and genomics have revealed fetal haemoglobin as a potential factor linking the stages in the development of preeclampsia. These techniques have revealed accumulation of haematopoietic stem cells expressing fetal $\mathrm{HbF}$ in placental vascular lumen. Cell free haemoglobin and its metabolites are toxic to tissue since they cause oxidative stress. ${ }^{5}$. The cell $\mathrm{Hb}$ binds to nitric oxide and causes vasoconstriction which leads to increased BP.

Alpha 1 microglobulin is a protein which has both enzymatic and non-enzymatic antioxidant properties. It binds and neutralizes free heme and toxic radicals. ${ }^{6}$ Serum concentrations are significantly elevated in maternal blood in first trimester for pregnant women subsequently developing preeclampsia. ${ }^{7}$

\section{Modified two stage model on basis of hbf hypothesis. ${ }^{8}$}

Shallow invasion of maternal spiral arteries

$$
\begin{gathered}
\downarrow \\
\text { Decreased blood flow to placenta } \\
\downarrow \quad \text { Stage } 1
\end{gathered}
$$

Increased placental synthesis of fetal HB $\downarrow$

Cell free fetal hb leakage into maternal circulation

$$
\begin{aligned}
& \downarrow \\
& \text { Oxidative stress } \\
& \downarrow \\
& \text { Upregulation of antioxidants } \\
& \downarrow \\
& \text { Endotheliosis in maternal vessels and glomerulus } \\
& \downarrow \\
& \text { Maternal hypertension and proteinuria } \\
& \text { Stage } 2
\end{aligned}
$$

\section{METHODS}

This was a prospective cohort study undertaken in the Department of Obstetrics and Gynaecology, ISO - KGH, between December 2016 to November 2017. This study was done to establish association between high levels of fetal haemoglobin and alpha 1 microglobulin in pregnant women between 10 to 16 weeks of gestational age and subsequent development of preeclampsia in these women. A total of 100 pregnant women were included in the study after getting informed written consent.

\section{Inclusion criteria}

- 10 to 16 weeks of pregnancy

- Singleton / multiple pregnancy

- Age group - 20 to 35 years

- Parity - both primigravida and multigravida

- $\quad$ BMI - 16 to $35 \mathrm{~kg} / \mathrm{m}^{2}$.

\section{Exclusion criteria}

- Diabetes mellitus

- Hypertension

- Renal disease

- Epilepsy

- Vascular disorders.

\section{Parameters studied}

- Fetal haemoglobin

- Alpha 1 microglobulin

\section{Procedure}

100 pregnant women attending antenatal clinic in ISO $\mathrm{KGH}$, willing to participate in the study were recruited after getting consent. Blood samples were collected between 10 to 16 weeks of GA and assayed using ELISA technique. They were managed according to Department protocol and followed till delivery. All participants were subjected to full history taking and clinical examination. General parameters like age, parity, BMI, BP measurement, gestational age at delivery, mode of delivery and perinatal outcome were compared between both groups. The values of fetal haemoglobin and alpha 1 microglobulin were correlated with the development of preeclampsia.

\section{Statistical analysis}

Data were collected and included in a database system and analysed by statistician. Parametric data were expressed as mean and standard deviation. It was analysed statistically using $\mathrm{t}$ - test. Non- parametric data were expressed as percentages and analyzed using chi square test. Receiver operator characteristics analysis was used to identify the optimal threshold values of fetal haemoglobin and alpha 1 microglobulin. Sensitivity, specificity, positive and negative predictive values of fetal haemoglobin and alpha 1 microglobulin were profiled by curves. Fetal haemoglobin and alpha 1 microglobulin levels were assayed using ELISA technique.

\section{RESULTS}

Age

In present study, there were $24 \%$ women between 21 to 24 years, $61 \%$ women between 25 to 28 years and $15 \%$ 
women between 29 to 32 years. (pearson chi - square $=0.819, \mathrm{P}=0.664$. .

\section{Parity}

There were $53.6 \%$ primi and $46 \%$ multi in present study.

\section{BMI}

Incidence of preeclampsia was found to be more among BMI group of 18.5 to $24.99 \mathrm{~kg} / \mathrm{m}^{2}$ (Pearson chi - square = 7.969. $\mathrm{P}=0.047)$. The mean BMI of women who developed preeclampsia was $22.5 \pm 5.6 \mathrm{~kg} / \mathrm{m}^{2}$. Mean BMI of normal pregnant women was $21.2 \pm 3.3 \mathrm{~kg} / \mathrm{m}^{2}$.

\section{Number of women who developed preeclampsia}

Out of 100 women, 56 women developed preeclampsia and 44 women did not develop preeclampsia.

\section{Blood pressure at admission}

The mean systolic, diastolic and mean arterial pressures of preeclamptic women were elevated at the time of admission in women who developed preeclampsia.

\section{Usage of antihypertensives}

Among the women who developed preeclampsia, 49 required 1 antihypertensive drug and 7 required 2 antihypertensive drugs.

\section{Type of labor}

Out of 56 women who had developed preeclampsia, labor was induced in 41 , spontaneous onset of labor in 3 women and 12 underwent elective caesarean section (Figure 1).

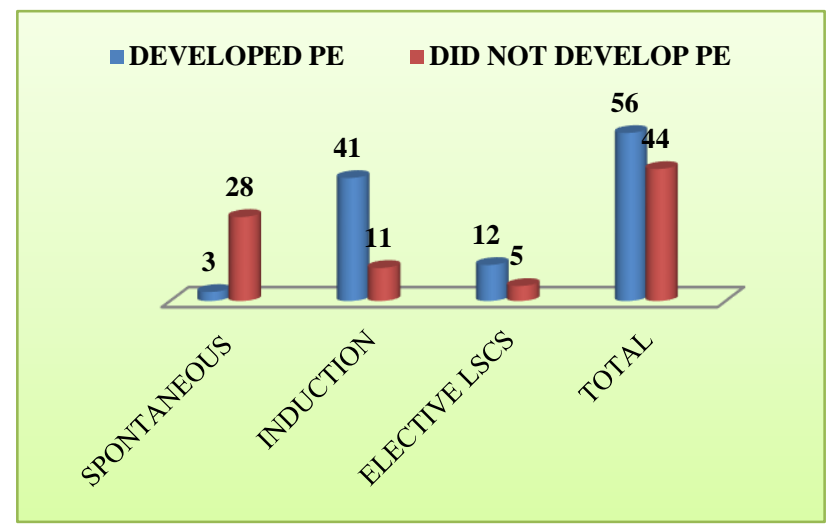

Figure 1: Type of labor.

\section{Mode of delivery}

Out of 56 women who developed preeclampsia, $51 \%$ delivered by vaginal delivery and $48 \%$ delivered by LSCS which is not statistically significant.
There was no statistical significance between mode of delivery and development of preeclampsia. (Pearson chi square $=5.636 . \mathrm{P}=0.018)$. There was no statistical significance between mode of delivery and values of fetal haemoglobin and alpha 1 microglobulin.

\section{Birth weight group}

Birth weight of majority of babies $(57 \%)$ were between 2.5 to $3.0 \mathrm{kgs}$. $38 \%$ of babies were above $3.0 \mathrm{kgs}$ and $5 \%$ of babies were less than $2.5 \mathrm{kgs}$.

There was no statistical significance between birth weight of babies and values of fetal haemoglobin and alpha 1 microglobulin (Pearson chi - square $=2.231 . \mathrm{P}=0.328$ ).

\section{Gestational age at delivery}

$51.8 \%$ of women who developed preeclampsia delivered around 37 weeks of gestation which was statistically significant (Figure 2) (Pearson chi - square $=68.419 . \mathrm{P}$ $<0.001)$. Mean gestational age of delivery was $37.5 \pm 0.6$ weeks.

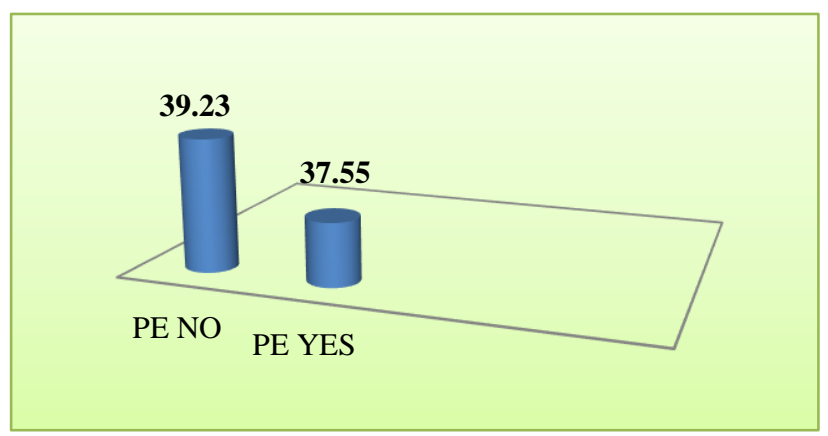

Figure 2: Gestational age at delivery.

There exists a statistical significance between high levels of alpha 1 microglobulin and development of preeclampsia (Figure 3).

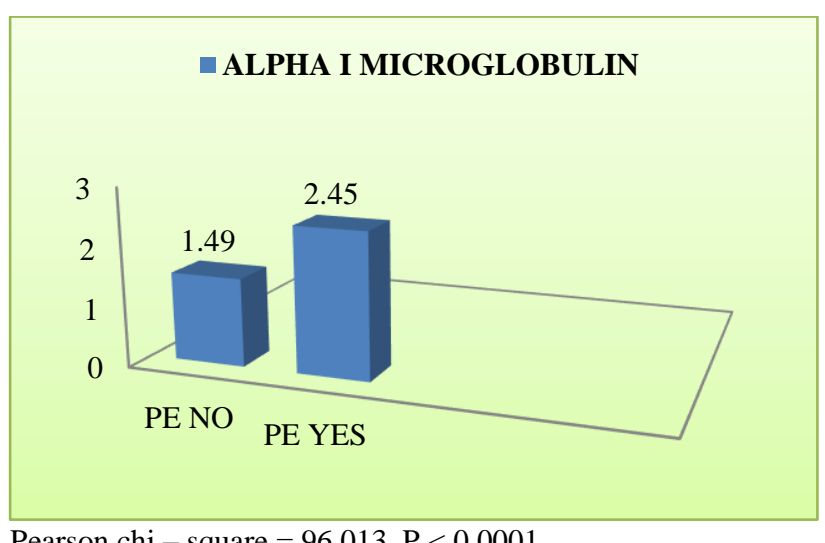

Pearson chi - square $=96.013 . \mathrm{P}<0.0001$.

Figure 3: Comparison of alpha 1 microglobulin for preeclampsia. 
There exists a statistical significance between high levels of fetal haemoglobin and development of preeclampsia (Figure 4).

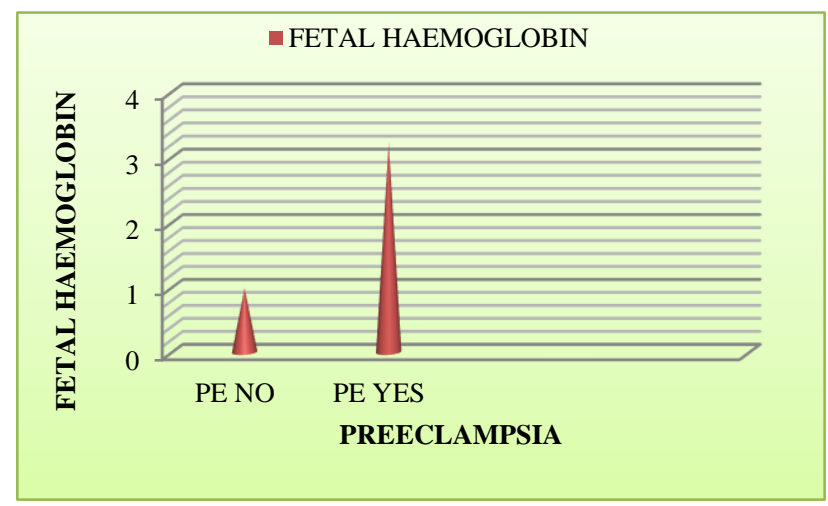

Figure 4: Comparison of fetal haemoglobin levels.

\section{Cut off values for alpha 1 microglobulin and fetal haemoglobin}

ROC curve (Table 1) was used.

The cut off value for alpha 1 microglobulin was $1.86 \mathrm{ng} / \mathrm{ml}$ (Table 2) above which most of the pregnant women developed preeclampsia. Study by Anderson et al showed a mean value of alpha 1 microglobulin of $1.95 \mathrm{ng} / \mathrm{ml}$ as cut off for predicting preeclampsia. ${ }^{5}$

The cut off value of fetal haemoglobin was $1.92 \mathrm{ng} / \mathrm{ml}$ (Table 2) above which most of the pregnant women developed preeclampsia. Similar study by Anderson et al showed a mean value of fetal hemoglobin as $1.38 \mathrm{ng} / \mathrm{ml}$ as cut off for predicting preeclampsia.

Table 1: Cut off values for alpha 1 microglobulin and fetal haemoglobin.

\begin{tabular}{|llllll|} 
Test result variables & Area & Std. error (a) & Asymptotic Sig(b) & \multicolumn{2}{c|}{ Asymptotic 95\% confidence interval } \\
Alpha 1 microglobulin & 1.000 & 0.000 & 0.000 & 1.000 & Upper bound \\
\hline Fetal haemoglobin & 0.998 & 0.003 & 0.000 & 0.992 & 1.000 \\
\hline
\end{tabular}

$\mathrm{a}$ - under the nonparametric assumption; $\mathrm{b}$ - Null hypothesis: true area $=0.5$.

The predictive values obtained in combination (Table 3) compare favorably with other preeclampsia biomarkers.

Table 2: Coordinates of the curve.

\begin{tabular}{|llll|}
\hline $\begin{array}{l}\text { Test result } \\
\text { variables }\end{array}$ & $\begin{array}{l}\text { Positive } \\
\text { If } \geq(\text { a })\end{array}$ & Sensitivity & $\begin{array}{l}1 \text { - } \\
\text { specificity }\end{array}$ \\
\hline $\begin{array}{l}\text { Alpha1 } \\
\text { microglobulin }\end{array}$ & 1.8600 & 1.000 & 0.023 \\
\hline $\begin{array}{l}\text { Fetal } \\
\text { haemoglobin }\end{array}$ & 1.9150 & 0.982 & 0.023 \\
\hline
\end{tabular}

Table 3: Predictive values obtained in combination.

\begin{tabular}{|l|l|}
\hline Predictive values & \\
\hline Sensitivity & $95.45 \%$ \\
\hline Specificity & $98.21 \%$ \\
\hline Positive predictive value & $97.67 \%$ \\
\hline Negative predictive value & $96.49 \%$ \\
\hline Diagnostic accuracy & $97 \%$ \\
\hline False positivity rate & $1.79 \%$ \\
\hline False negativity rate & $4.55 \%$ \\
\hline Positive likelihood ratio & 53.45 \\
\hline Negative likelihood ratio & 0.05 \\
\hline
\end{tabular}

\section{DISCUSSION}

This was a prospective cohort study to establish association between high levels of fetal haemoglobin and alpha 1 microglobulin in pregnant women of 10 to 16 weeks of GA and subsequent development of preeclampsia.

\section{Baseline characteristics}

Majority of women who developed preeclampsia belong to age group of 25 to 28 years. However, there was no statistical significance in development of preeclampsia with respect to age group.

There was no statistical significance between values of fetal haemoglobin and alpha 1 microglobulin with respect to age of pregnant women.

The mean age of the women in the study was 26.222 years. The mean age of women who developed preeclampsia was $26.3 \pm 2.2$ years. This was similar to the studies reported in literature.

Even though the incidence of preeclampsia was found to be more among primi, there was no statistical significance in parity with respect to preeclampsia (Pearson chi - square $=0.305 . \mathrm{P}=0.581)$.

Moore et al, in their study found $71 \%$ of women as primigravida. ${ }^{9}$ In Luealonet study $64.1 \%$ were primigravida. ${ }^{10}$ In a study on biomarkers for preeclampsia by Kusanovic et al, $61.3 \%$ were primigravida. ${ }^{11}$ There was no statistical significance between BMI and development of preeclampsia. There was no statistical 
significance between levels of fetal haemoglobin and alpha 1 microglobulin and BMI of pregnant women.

In a study by Anderson et al, BMI of women who developed preeclampsia was $26.9 \mathrm{~kg} / \mathrm{m}^{2}$ this difference was due to different ethnicity, race, socioeconomic status, eating habits etc. ${ }^{12}$

The mean arterial pressure was $89.3 \mathrm{~mm}$ of $\mathrm{Hg}$ in normotensive women and $111.3 \mathrm{~mm}$ of $\mathrm{Hg}$ in women who developed preeclampsia.

All women in the study who developed preeclampsia required one or more antihypertensives for control of blood pressure.

In the study by Podynow et al, $43 \%$ of women required antihypertensive medication in the antenatal period. ${ }^{13}$ The difference in the requirements of antihypertensives in the antenatal period may be because all groups of hypertensive disorders were included in all the studies. Tufnell et al used antihypertensives in $53 \%$ of women with preeclampsia in their study. ${ }^{1}$

\section{Type of labor}

The induction rate was higher in women who developed preeclampsia compared to women who did not develop preeclampsia.

\section{Mode of delivery}

In the study by Lisa et al, caesarean delivery was significantly more in preeclamptic women. ${ }^{14}$ In present study, there was no significant difference between caesarean section and vaginal delivery.

\section{Birth weight group}

In present study, mean birth weight in preeclamptic women was $2.75 \mathrm{~kg}$. This is in accordance with the study by Anderson et al, where the mean birth weight was $2.716 \mathrm{~kg} .{ }^{12}$

\section{GA at delivery}

Most of the women who developed preeclampsia delivered around 37 weeks. This was due to higher induction rates in these women. In a study by Anderson et al, the mean gestational age was 36.7 weeks. ${ }^{12}$ Luealon et al studied risk factors of preeclampsia and found that the mean gestational age at delivery was $36.5 \pm 3.1$ weeks. ${ }^{10}$ This was due to the fact that all preeclamptic women were induced at 37 weeks.

\section{Alpha 1 microglobulin}

In present study, sensitivity of alpha 1 microglobulin for predicting preeclampsia was $100 \%$ and specificity was $25 \%$.
Study by Anderson et al showed a mean value of alpha 1 microglobulin of $1.95 \mathrm{ng} / \mathrm{ml}$ as cut off for predicting preeclampsia. ${ }^{12}$ Present study also supports the fact. The cut off value of alpha 1 microglobulin in present study was $1.86 \mathrm{ng} / \mathrm{ml}$ after applying ROC curve.

Based on the research work, Recombinant alpha 1 microglobulin (RMC - 035) has been identified now as a candidate to become the first pharmacological treatment for preeclampsia. $^{15}$

\section{Fetal haemoglobin}

In present study, sensitivity of fetal haemoglobin was $98.2 \%$ and specificity was $23 \%$.

Study by Anderson et al showed a mean value of fetal haemoglobin as $1.38 \mathrm{ng} / \mathrm{ml}$ as cut off for predicting preeclampsia. ${ }^{12}$ In present study, cut off value for fetal haemoglobin for predicting preeclampsia was $1.91 \mathrm{ng} / \mathrm{ml}$.

The combined sensitivity was $95.45 \%$ and specificity of both the tests was $98.21 \%$. in a study by Anderson et al, combined sensitivity was $90 \%$ at $30 \%$ screen positivity rate. $^{12}$

\section{CONCLUSION}

Higher values of fetal hemoglobin and alpha 1 microglobulin in pregnant women between 10 to 16 weeks gestational age positively correlates with development of preeclampsia in those women. The predictive values obtained when the two tests were used in combination compare favourably with other preeclampsia markers so that $\mathrm{HbF}$ and alpha 1 microglobulin can be used as biomarkers in late first trimester and early second trimester of pregnancy for detecting preeclampsia. Termination of pregnancy is the only definitive treatment of preeclampsia at present. Further large-scale research works are needed so that recombinant alpha 1 microglobulin can be used as an effective drug in the management of preeclampsia.

\section{Funding: No funding sources \\ Conflict of interest: None declared}

Ethical approval: The study was approved by the Institutional Ethics Committee

\section{REFERENCES}

1. Tuffnell DJ, Jankowicz D, Lindow SW, Lyons G, Mason GC, Russell IF, et al, Yorkshire Obstetric Critical Care Group. Outcomes of severe preeclampsia/eclampsia in Yorkshire 1999/2003. BJOG: Int J Obstet Gynaecol. 2005;112(7):875-80.

2. Brosens JJ, Pijnenborg R, Brosens IA. The myometrial junctional zone spiral arteries in normal and abnormal pregnancies: a review of the literature. Am J Obstet Gynecol. 2002;187(5):1416-23. 
3. Young BC, Levine RJ, Karumanchi SA. Pathogenesisof preeclampsia. Annu Rev Pathol. 2010;5:173-92.

4. Gram M, Anderson UD, Johansson ME, EdströmHägerwall A, Larsson I, Jälmby M, et al. The human endogenous protection system against cell-free hemoglobin and heme is overwhelmed in preeclampsia and provides potential biomarkers and clinical indicators. PloS one. 2015;10(9):e0138111.

5. Hansson SR, Gram M, Åkerström B. Fetal hemoglobin in preeclampsia: a new causative factor, a tool for prediction/diagnosis and a potential target for therapy. Curr Opin Obstet Gynecol. 2013;25(6):448-55.

6. May K, Rosenlöf L, Olsson MG, Centlow M, Mörgelin M, Larsson I, et al. Perfusion of human placenta with hemoglobin introduces preeclampsialike injuries that are prevented by $\alpha 1$-microglobulin. Placenta. 2011;32(4):323-32.

7. Hansson SR, Nääv A, Erlandsson L. Oxidative stress in preeclampsia and the role of free fetal hemoglobin. Frontiers Physiol. 2015;5:516.

8. Roberts JM, Hubel CA. The two stage model of preeclampsia: variations on the theme. Placenta. 2009;30:32-7.

9. Moore MP, Redman CW. Case-control study of severe pre-eclampsia of early onset. Br Med J (Clin Res Ed). 1983;287(6392):580-3.

10. Luealon P, Phupong V. Risk factors of preeclampsia in Thai women. J Med Assoc Thai. 2010;93(6):6616.
11. Kusanovic JP, Romero R, Chaiworapongsa T, Erez O, Mittal P, Vaisbuch E, Mazaki-Tovi S, et al. A prospective cohort study of the value of maternal plasma concentrations of angiogenic and antiangiogenic factors in early pregnancy and midtrimester in the identification of patients destined to develop preeclampsia. J Maternal-Fetal Neonatal Med. 2009;22(11):1021-38.

12. Anderson UD, Olsson MG, Rutardóttir S, Centlow $\mathrm{M}$, Kristensen $\mathrm{KH}$, Isberg $\mathrm{PE}$, et al. Fetal hemoglobin and $\alpha 1$-microglobulin as first-and early second-trimester predictive biomarkers for preeclampsia. Am J Obstet Gynecol. 2011;204(6):520-e1.

13. Podynow T and August P. antihypertensive drugs in pregnancy. Semin Nephrol. 2011;31(1):70-85.

14. Simmons LA, Hennesey A, Gillin AG, Jeremy RW. Uteroplacental blood flow and preeclamptic pregnancy. Br J Obstet Gynaecol. 2000;107:678-85.

15. Gunnarsson R, Åkerström B, Hansson SR, Gram M. Recombinant alpha-1-microglobulin: a potential treatment for preeclampsia. Drug Discovery Today. 2017;22(4):736-43.

Cite this article as: Vijaya $\mathrm{S}$, Mahalakshmi M, Inbapriyanka I. Fetal haemoglobin and alpha 1 microglobulin as biochemical markers in predicting preeclampsia in late first trimester and early second trimester of pregnancy. Int J Reprod Contracept Obstet Gynecol 2018;7:3226-31. 